\title{
Effects of a practical resistance band training intervention on muscle soreness during pregnancy: A pilot study
}

\author{
Erin E White ${ }^{*}$, Melissa Richards², Ashley Kloeckner1, Taylor Kuhn¹, Jalana Larson'1, Kayleigh Lawrence1, \\ Emily Passint 1 , Evan Peterson'1, Kaila Potting1, Megan Williams¹
}

\begin{abstract}
${ }^{*}$ Correspondence
Erin E White

Winona State University Health,

Exercise and Rehabilitative Sciences

Department Maxwell 366 PO Box 5838

Winona, Minnesota USA

Email: EWhite@winona.edu

Telephone number: 507.457.2577

'Winona State University Health,

Exercise and Rehabilitative Sciences

Department Winona, Minnesota USA

2Olmsted Medical Center Department of

Obstetrics and Gynecology Rochester,

Minnesota USA

Received: Feb 4, 2019

Accepted: Mar 23, 2019

Published: Apr 3, 2019

(C)2019 Erin E White et al; licensee OA Journal of Clinical Case Reports. This is an Open Access article distributed under the terms of the Creative Commons Attribution License (http:// creativecommons.org/licenses/by/4.0), which permits unrestricted use, distribution, and reproduction in any medium, provided the original work is properly credited.
\end{abstract}

\begin{abstract}
Background: Mothers often experience muscle soreness following labor and delivery; however, this has yet to be examined. Purpose: To determine the effects of resistance bands on maternal muscle soreness when performed during the second and third trimesters of pregnancy.

Methods: Women were randomized to an exercise $(n=12)$ or standard-care $(n=13)$ groups and completed surveys regarding muscle soreness. The exercise group performed a 15 week resistance band program 3 times/wk. Maternal, newborn, and delivery outcomes were measured. Change scores were calculated and comparisons were made using independent ttests and chi-square tests.
\end{abstract}

Results: Twenty-five women participated, mean age was $26.5 \pm$ 3.4 years. There were no significant differences $(p>0.05)$ in muscle soreness and maternal and newborn outcomes. Mode of delivery was significantly different ( $p=0.05$ ) with the exercise group having more vaginal births (91.7\%) compared to the standard care group (61.5\%).

Conclusions: Muscle soreness was not significantly different, however, the mean values were in the expected direction. Further, there was a higher percentage of women in the exercise group having vaginal deliveries. Thus, while the sample size was small, these pilot findings have clinical importance, even if they are not statistically significant due to limited

power. The use of resistance bands may be a practical intervention to increase the percentage of vaginal deliveries, the preferred mode of delivery. Confirming these results with a larger sample size is necessary.

Keywords: Exercise, Gestation, Vaginal birth, Pain management, Muscle soreness, Cesarean section, Pregnancy, Resistance training.

\section{Introduction}

The American Congress of Obstetricians and Gynecologists (ACOG) published the first physical activity guidelines during pregnancy in 1985 and have continually updated them currently recommending all healthy pregnant women perform at least 150 minutes of moderate-intensity aerobic activity every week [1], which is the same activity recommendation for non-pregnant women. Similarly, resistance training is recommended by major health organizations for improving health in the general population [2], however, no well-established guidelines exist regarding resistance training during pregnancy. For pregnant women, light resistance exercise training may be better tolerated than 
aerobic training [3] because of the ability to switch between machines and free weights to accommodate their changing bodies as pregnancy continues [4]. While there are no guidelines for resistance training during pregnancy, evidence is mounting demonstrating resistance bands are a safe and effective method of training such that there is no negative impact on infant birth weight and length [3] . Nevertheless, many women do not engage in resistance training frequently during pregnancy [4]. From anecdotal evidence, a common complaint after birth is muscle soreness, which is caused by maternal exertion from repeated and sustained contractions during labor and delivery. It is possible that resistance training during pregnancy may decrease potential muscle soreness following labor and delivery due to an increased ability of the muscles to perform repeated contractions. Thus, examining the relationship between resistance training and muscle soreness following delivery is worthy of more research. Presently, to the authors' knowledge, there is no research regarding muscle soreness following labor and delivery. Therefore, finding a way to mitigate a common complaint among pregnant women would have substantial clinical implications.

Furthermore, while some groups have examined the effects of resistance training during pregnancy, a limiting factor was adherence of attending group exercise sessions. Haakstad and B $\varnothing$ (2014) studied whether pelvic girdle and low back pain may be prevented or treated in pregnant women who participated in a twice weekly, 30 minute group fitness class along with 30 minutes of self-imposed moderate physical activity on the remaining weekdays [ㅁ] . Of the 52 women who were randomly placed into the exercise group, only $27 \%$ had $100 \%$ adherence and $40 \%$ had $\geq 80 \%$ adherence. The low adherence affected the power of the study which showed no statistically significant differences between groups regarding pelvic girdle and low back pain [5]. To our knowledge, no investigators have taken an approach in a randomized controlled trial in which the exercise intervention is limited in an effort to increase adherence and thus make it more practical. Thus, developing a practical exercise intervention may increase adherence of the participants.
Therefore, the purpose of this pilot study was to determine the effects of a practical intervention using resistance bands on maternal muscle soreness when performed during the second and third trimesters of pregnancy. It was hypothesized there would be a decrease in upper body muscle soreness and lower body muscle soreness post-birth in the exercise group when compared to women in the standard care group, while also demonstrating no retarded growth of the fetus or maternal labor/ delivery complications due to the training regimen.

\section{Materials and Methods}

This pilot study was a prospective, randomizedcontrolled trial conducted by Winona State University in collaboration with Winona Health, a local community healthcare facility in Winona, Minnesota, United States. Inclusion criteria were healthy patients under supervision of an obstetrical provider at Winona Health, aged 20 to 35 years with a noncomplicated singleton pregnancy, and approved by their obstetrical provider. Other inclusion criteria were women who spoke and read English, had a prepregnancy body mass index (BMI) less than $35 \mathrm{~kg} / \mathrm{m} 2$, and a gestational age of 12 to 25 weeks at time of recruitment. To recruit the largest sample size possible, both primiparous and multiparous women were included in this study. Exclusion criteria were any pregnancy complications that led to an early birth or if they had previously participated in resistance training (1x/week in the past 6 months). The Institutional Review Board at Winona State University and Winona Health reviewed and approved the study design and protocol.

\section{Recruitment of Participants}

Women were recruited at Winona Health via brochures/flyers as well as during their regularly scheduled prenatal visits. Women were informed about the purpose of the pilot study and provided written informed consent. Participation resulted in reimbursement for their time and dedication to the study in the form of a gift card. A rolling enrollment process was used.

\section{Surveys}

Once enrolled in the study, participants completed a pre-intervention survey which consisted of the Pregnancy Physical Activity Questionnaire (PPAQ) []. muscle soreness questions for upper and lower body 
$[\underline{7}, \underline{8}]$, and demographic questions. Women completed the PPAQ for two separate time points, 1) prepregnancy physical activity levels and 2) current physical activity levels, which consisted of the time frame at which they were enrolled. The muscle soreness questions were based on a 1-10 Likert scale [7]; the wording was, "Please choose a number that represents your overall LOWER BODY muscle soreness. ( 1 = normal, 10 = very, very sore.)" And "Please choose a number that represents your overall UPPER BODY muscle soreness. ( 1 = normal, 10 = very, very sore.)" To the investigators' knowledge, there are no validated instruments to determine muscle soreness during pregnancy, thus scales for muscle soreness that have been validated in the general population were used and a change score was calculated to minimize bias of the scale [7]. The pre-intervention survey was taken between 12 to 25 weeks' of gestation and included questions from the PPAQ regarding their prepregnancy activity levels and upper and lower body muscle soreness. Once the pre-intervention survey was completed, women were randomly assigned, via a computer-generated randomization process, to either the exercise group or standard care group. Randomization to either group occurred after the pre-intervention survey to ensure results were not influenced by group assignment. Lastly, women completed a post-birth survey, within 12-72 hours after delivery consisting of the same 2 questions regarding upper and lower body muscle soreness.

\section{Standard Care (Control) Group}

Women in the standard care (control) group reviewed the American Congress of Obstetricians and Gynecologists guidelines (2011) with their healthcare provider for physical activity and the women were not discouraged from exercising on their own. This group's participation was solely based on completion of the pre-intervention and post-birth surveys.

\section{Exercise Group}

Women in the exercise group received the same counseling regarding exercise in pregnancy recommendations from their healthcare provider. In addition, they performed 3 resistance band training sessions each week for approximately 15 weeks at a somewhat hard intensity (5-6 on a 1-10 Ratings of Perceived Exertion (RPE) scale). The resistance band training sessions started between 22 to 25 weeks' gestational age and ended upon birth ( 37-40 weeks gestation). To optimize the practicality of the intervention well-trained co-investigators ("trainers") supervised only one of the sessions to teach appropriate technique, breathing patterns, and modifications that were needed as the pregnancy progressed. Each trainer was responsible for talking with the women to determine the appropriate intensity based off the RPE scale that included both numeric values and pictures associated with intensity level. The other 2 sessions were completed independently by the participant at a location of their choosing (which was most commonly their home). Women were contacted by their trainer via phone call or text message weekly to ensure adherence and to answer any questions regarding the exercise program. Theraband ${ }^{\circledR}$ resistance bands were used in three different colors (yellow, red, and green) to represent increasing levels of difficulty. The women followed the exercise program listed in Table 1. Progressions and modifications occurred on an individual basis to maintain an RPE of 5-6.

Table 1. Resistance Training Program Performed by Participants

\begin{tabular}{|c|c|}
\hline Aspect of Program & Description \\
\hline Warm-Up & $\begin{array}{l}\text { 5-10 minutes of light walking and/or } \\
\text { stretching }\end{array}$ \\
\hline Frequency & 3 days/week ( 1 supervised, 2 at home) \\
\hline Intensity & $\begin{array}{l}2 \text { sets of } 15 \text { repetitions } \\
5-6 \text { on a } 1-10 \text { RPE scale (somewhat hard) } \\
\text { [20] }\end{array}$ \\
\hline Time & 30-35 minutes/session \\
\hline Type & Resistance training with Therabands ${ }^{\circledR}$ \\
\hline Rest Periods & $<1$ minute (circuit-type training) \\
\hline Progression & $\begin{array}{l}\text { Increase to } 2 \text { sets of } 20 \text { repetitions, } 3 \text { sets } \\
\text { of } 15 \text { repetitions, then } 3 \text { sets of } 20 \\
\text { repetitions } \\
\text { Yellow, red, green Therabands }{ }^{\circledR} \text { (Least to } \\
\text { most resistance) }\end{array}$ \\
\hline $\begin{array}{l}\text { Exercises } \\
\text { Performed }\end{array}$ & $\begin{array}{l}\text { Hip abduction, Seated spinal twists, Seated } \\
\text { leg curls, Seated knee extensions, Triceps } \\
\text { extensions, Reverse pec fly, Biceps curls, } \\
\text { Anterior/posterior pelvic tilts, Kegels }\end{array}$ \\
\hline Cool-Down & $\begin{array}{l}\text { 5-10 minutes of light walking and/or } \\
\text { stretching }\end{array}$ \\
\hline
\end{tabular}

Abbreviations: RPE, Ratings of Perceived Exertion. 


\section{Outcomes Measured}

\section{Maternal outcomes}

Maternal weight gain ( $\mathrm{kg}$ ) was acquired from medical records and calculated by subtracting the mother's prepregnancy weight by the weight taken at her last prenatal appointment. Upper and lower body muscle soreness post-birth were determined by the mother completing the survey. A change score for upper and lower body muscle soreness was calculated by taking the pre-intervention score and subtracting the postbirth score (i.e., pre minus post).

\section{Birth outcomes}

Gestational age at birth (days), length of second stage of labor (min), length of maternal effort (i.e., amount of time of pushing), and mode of birth were acquired from medical records. Gestational age was calculated by summing the total days the woman was pregnant. Length of maternal effort was calculated from the time the woman began pushing until she gave birth. The second stage of labor was calculated from the time the woman's cervix was dilated to 10 centimeters until she gave birth. The mode of birth was categorized into 3 groups: vaginal (spontaneous or operative), unscheduled cesarean section, and scheduled cesarean section.

\section{Newborn outcomes}

Newborn weight $(\mathrm{kg})$, length $(\mathrm{cm})$, Apgar scores at one and 5 minutes, and maternal parity were acquired from medical records.

\section{Statistical Analyses}

Descriptive statistics were used to describe the sample, which included maternal age, ethnicity, education level, marital status, income, parity, previous physical activity, current physical activity, and prepregnancy BMI. One-tailed independent ttests were used to analyze all maternal outcomes and differences in length of second stage of labor and length of maternal effort. A two-tailed independent t-test was used to analyze the difference between gestational age at birth. A chisquare test was used to compare mode of birth. Twotailed independent t-tests were used to analyze all newborn outcomes. All statistical analyses were completed using the Statistical Package for Social Science (SPSS) 23 and the level of statistical significance was set to $p \leq .05$.

\section{Results}

Thirty-one women were enrolled in the pilot study, however, 5 women dropped out, and one woman from the standard care group was excluded from analysis due to the fact she delivered at another facility, leaving a total sample size of 25 . Among the dropouts in the standard care group ( $n=2)$, one woman changed obstetrical providers and the other did not complete anything beyond the preintervention survey. The remaining 3 women were randomized to the exercise group and dropped out before they began their first exercise session. Of the 25 women who completed the study, 12 were randomly assigned to the exercise group and 13 were randomly assigned to the standard care group. There were no significant differences in demographic characteristics, prepregnancy or current physical activity levels, and pre-intervention upper and lower body muscle soreness between the exercise group and the standard care group as shown in Table 2.

Table 2. Demographic Characteristics of Exercise and Standard Care Groups

\begin{tabular}{|c|c|c|c|}
\hline $\begin{array}{l}\text { Demographic } \\
\text { Characteristics }\end{array}$ & $\begin{array}{l}\text { Exercise } \\
\text { Group }(n=12)\end{array}$ & $\begin{array}{l}\text { Standard } \\
\text { Care }(n=13)\end{array}$ & $\begin{array}{l}\mathrm{p}- \\
\text { Value }\end{array}$ \\
\hline $\begin{array}{l}\text { Age at birth, mean (SD), } \\
\text { year }\end{array}$ & $27.1(4.3)$ & $26.0(2.3)$ & 0.45 \\
\hline Race/ethnicity, n (\%) & & & 0.37 \\
\hline White & $12(100)$ & $11(84.6)$ & \\
\hline Other & $0(0)$ & $2(14.1)$ & \\
\hline Education level, n (\%) & & & 0.17 \\
\hline Grade 12 or GED & $1(8.3)$ & $4(30.8)$ & \\
\hline College 1 year to 3 years & $3(25.0)$ & $5(38.5)$ & \\
\hline College 4 years or more & $8(66.7)$ & $4(30.8)$ & \\
\hline Marital Status, n (\%) & & & 0.44 \\
\hline Married & $11(88.9)$ & $8(61.5)$ & \\
\hline Never married & $0(0)$ & $1(7.7)$ & \\
\hline Divorced & $0(0)$ & $1(7.7)$ & \\
\hline Widowed/Widower & $0(0)$ & $1(7.7)$ & \\
\hline Living with partner & $1(11.1)$ & $2(15.4)$ & \\
\hline Income, n (\%) & & & 0.26 \\
\hline$\leq \$ 34,999$ & $2(16.7)$ & $8(61.6)$ & \\
\hline$\$ 35,000-\$ 74,999$ & $5(41.6)$ & $2(15.4)$ & \\
\hline$\geq \$ 75,000$ & $5(41.7)$ & $3(23.1)$ & \\
\hline
\end{tabular}




\begin{tabular}{|c|c|c|c|}
\hline $\begin{array}{l}\text { Demographic } \\
\text { Characteristics }\end{array}$ & $\begin{array}{l}\text { Exercise } \\
\text { Group }(n=12)\end{array}$ & $\begin{array}{l}\text { Standard } \\
\text { Care }(n=13)\end{array}$ & $\begin{array}{l}\mathrm{p}- \\
\text { Value }\end{array}$ \\
\hline $\begin{array}{l}\text { Prepregnancy BMI, mean } \\
\text { (SD), } \mathrm{kg} / \mathrm{m} 2\end{array}$ & $25.5(4.9)$ & $26.5(5.0)$ & 0.63 \\
\hline Primiparous, n (\%) & $7(58.3)$ & $10(76.9)$ & 0.57 \\
\hline $\begin{array}{l}\text { Prepregnancy Physical } \\
\text { Activity, mean (SD), MET-hr/ } \\
\text { wk }\end{array}$ & $342.5(166.5)$ & $313.5(146.1)$ & 0.67 \\
\hline $\begin{array}{l}\text { Current Physical Activity, } \\
\text { mean (SD), MET-hr/wk }\end{array}$ & $299.8(148.9)$ & $\begin{array}{l}334.3 \\
(256.2)\end{array}$ & 0.69 \\
\hline $\begin{array}{l}\text { Pre-intervention Upper } \\
\text { Body Muscle Soreness, } \\
\text { mean (SD) }\end{array}$ & $2.3(1.8)$ & $2.2(1.2)$ & 0.77 \\
\hline $\begin{array}{l}\text { Pre-intervention Lower } \\
\text { Body Muscle Soreness, } \\
\text { mean (SD) }\end{array}$ & $2.7(1.7)$ & $2.6(1.7)$ & 0.94 \\
\hline
\end{tabular}

Abbreviations: BMI, Body Mass Index; GED, General Educational Development; $\mathrm{m} / \mathrm{kg} 2$, meters per kilogram squared; MET, Metabolic Equivalent Unit; hr/wk, hours per week.

The majority of women were White, well-educated, married, and middle to upper class. Women participating in the exercise group experienced no major adverse health effects during the program or exercise-related injuries. The overall adherence rate in the exercise group was $>98 \%$ of all training sessions (approximately 45 total training sessions [3 sessions/week $\times 15$ weeks])

\section{Maternal Outcomes}

There was no statistically significant difference in maternal weight gain between the exercise and standard care groups (Table 3). On average, the women gained $13.9 \pm 5.9 \mathrm{~kg}$ and $12.0 \pm 5.6 \mathrm{~kg}$ in the exercise and standard care groups, respectively.

Table 3. Maternal Outcomes for Exercise and Standard Care Groups

\begin{tabular}{|l|l|l|r|}
\hline Maternal Outcomes & $\begin{array}{l}\text { Exercise } \\
\text { Group }(n=12)\end{array}$ & $\begin{array}{l}\text { Standard } \\
\text { Care }(n=13)\end{array}$ & p-Value \\
\hline $\begin{array}{l}\text { Maternal weight gain, } \\
\text { mean (SD), kg }\end{array}$ & $13.9(5.9)$ & $12.0(5.6)$ & 0.21 \\
\hline $\begin{array}{l}\text { Upper body muscle } \\
\text { soreness change score, } \\
\text { mean (SD)a }\end{array}$ & $0.50(2.5)$ & $0.00(2.2)$ & 0.30 \\
\hline $\begin{array}{l}\text { Lower body muscle } \\
\text { soreness change score, } \\
\text { mean (SD)a }\end{array}$ & $-0.50(2.2)$ & $-1.80(3.2)$ & 0.13 \\
\hline
\end{tabular}

Abbreviations: $\mathrm{kg}$, kilograms

aUpper body and lower body muscle soreness were based on a 1-10 Likert scale, where 1=normal and 10=very, very sore
There was also no statistically significant difference in upper body muscle soreness, between the exercise and standard care groups (Table 3). A change score was calculated, thus, a negative change score demonstrated an increase in muscle soreness from early pregnancy to post-birth (i.e., 2 minus $4=-2$, indicating soreness increased after birth). Upper body muscle soreness values in early pregnancy were $2.2 \pm 1.3$ and $2.3 \pm 1.8$ in the standard care and exercise groups, respectively. Post-birth, the upper body muscle soreness values were $2.2 \pm 1.7$ and $1.8 \pm$ 1.4 in the standard care and exercise groups, respectively. The change in upper body muscle soreness did not change for the standard care group and decreased by an average of 0.50 for the exercise group (Figure 1). While the mean change values for upper body muscle soreness post-birth were in the expected direction, there was no statistical significance found between the groups $(p=.30)$.

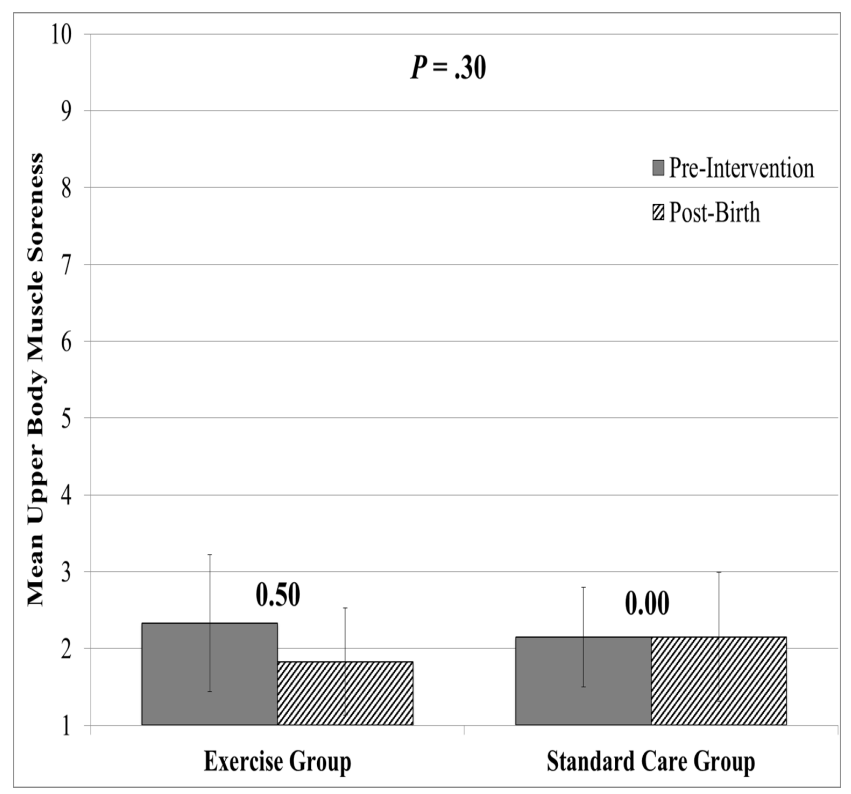

Figure 1. Change in Upper Body Muscle Soreness Post-Birth in Exercise and Standard Care Groups. Mean upper body muscle soreness scores ( $1=$ normal and $10=$ very, very sore) for the exercise and standard care groups. The change score was calculated by subtracting the pre-intervention score by the post-birth score. No statistically significant difference in change score was found between the exercise and standard care groups, $P=.30$, however, the mean values were in the expected direction.

Likewise, there was no statistically significant difference between the exercise and standard care groups for the change in lower body muscle soreness post-birth $(p=.14)$ as seen in Table 3. Lower body muscle soreness values in early pregnancy were $2.6 \pm$ 1.7 and $2.7 \pm 1.7$ in the standard care and exercise 
groups, respectively. Post-birth, the lower body muscle soreness values were $4.4 \pm 3.1$ and $3.2 \pm 2.1$ in the standard care and exercise groups, respectively. The change in lower body muscle soreness was $-1.8 \pm$ 3.2 for the standard care group and $-0.50 \pm 2.2$ for the exercise group (Figure 2). While the mean change values for lower body muscle soreness post-birth were in the expected direction, there was no statistical significance found between the groups $(p=$ .13).

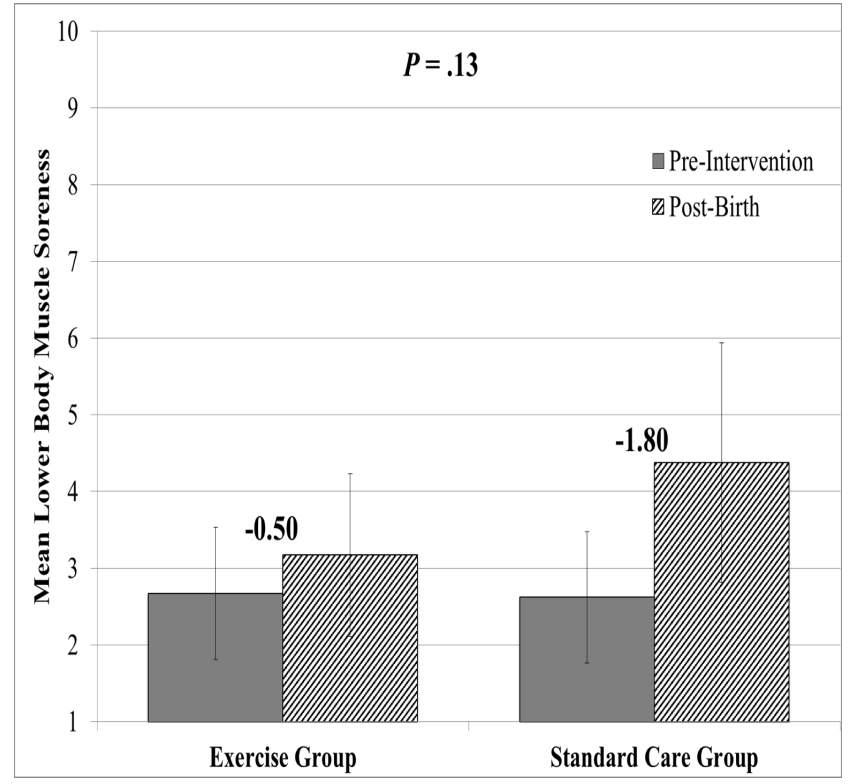

Figure 2. Change in Lower Body Muscle Soreness Post-Birth in Exercise and Standard Care Groups. Mean lower body muscle soreness scores ( $1=$ normal and $10=$ very, very sore) for the exercise and standard care groups. The change score was calculated by subtracting the pre-intervention score by the post-birth score. No statistically significant difference in change score was found between the exercise and standard care groups, $\mathrm{P}=.13$, however, the mean values were in the expected direction.

\section{Birth Outcomes}

There were no statistically significant differences for gestational age at birth $(p=.60)$, length of maternal effort ( $p=.94)$, or length of second stage of labor ( $p$ $=.94$ ) between the exercise and standard care groups (Table 4). However, there was a higher percentage of vaginal births in the exercise group $(91.7 \%, \mathrm{n}=11)$ compared to the standard care group (61.5\%, $\mathrm{n}=8)$, a difference of $30.2 \%$, which was statistically significant $(p=.05)$. Additionally, there were no unscheduled cesarean births in the exercise group, while there were $4(30.8 \%)$ in the standard care group.
Table 4. Birth Outcomes in the Exercise and Standard Care Groups

\begin{tabular}{|c|c|c|c|}
\hline Birth Outcomes & $\begin{array}{l}\text { Exercise Group } \\
(n=12)\end{array}$ & $\begin{array}{l}\text { Standard } \\
\text { Care }(n=13)\end{array}$ & $p$-Value \\
\hline $\begin{array}{l}\text { Gestational age at } \\
\text { birth, mean (SD), days }\end{array}$ & $276.5(7.5)$ & $274.8(7.9)$ & 0.60 \\
\hline $\begin{array}{l}\text { Length of second } \\
\text { stage of labor, mean } \\
\text { (SD) min }\end{array}$ & 75.0 (56.9) & 72.7 (67.5) & 0.94 \\
\hline $\begin{array}{l}\text { Length of maternal } \\
\text { effort, mean (SD) min }\end{array}$ & $57.3(32.4)$ & $56.0(47.3)$ & 0.94 \\
\hline Mode of birth & & & 0.05 \\
\hline Vaginal, n (\%) & 11 (91.7) & $8(61.5)$ & \\
\hline $\begin{array}{l}\text { Unscheduled } \\
\text { cesarean birth, n (\%) }\end{array}$ & $0(0)$ & $4(30.8)$ & \\
\hline $\begin{array}{l}\text { Scheduled cesarean } \\
\text { birth, n (\%) }\end{array}$ & $1(8.3)$ & $1(7.7)$ & \\
\hline
\end{tabular}

Abbreviations: min, minutes; SD, Standard Deviation.

\section{Newborn Outcomes}

There were no significant differences found between the exercise and standard care groups for newborn weight ( $p=.13)$, newborn length $(p=.35)$, Apgar score at one minute $(p=.64)$, and Apgar score at 5 minutes ( $p=.86)$ (Table 5).

Table 5. Newborn Outcomes in the Exercise and Standard Care Groups

\begin{tabular}{|l|l|l|r|}
\hline Newborn Outcomes & $\begin{array}{l}\text { Exercise } \\
\text { Group }(\mathrm{n}=12)\end{array}$ & $\begin{array}{l}\text { Standard } \\
\text { Care }(\mathrm{n}=13)\end{array}$ & p-Value \\
\hline Weight, mean (SD), kg & $3.5(0.4)$ & $3.2(0.5)$ & 0.13 \\
\hline Length, mean (SD), cm & $50.4(2.2)$ & $49.5(2.8)$ & 0.35 \\
\hline $\begin{array}{l}\text { Apgar score at 1 min, } \\
\text { mean (SD)c }\end{array}$ & $7.7(2.3)$ & $8.1(2.0)$ & 0.64 \\
\hline $\begin{array}{l}\text { Apgar Score at 5 min, } \\
\text { mean (SD)c }\end{array}$ & $8.5(2.1)$ & $8.6(1.1)$ & 0.86 \\
\hline
\end{tabular}

Abbreviations: Apgar, Appearance Pulse Grimace Activity and Respiration; cm, centimeters; kg, kilograms

cApgar at 1 and 5 minutes is based on the sum of 5 wellness criteria on a 0-2 Likert scale

\section{Discussion}

Due to the absence of research regarding muscle soreness following labor and delivery, more research is necessary. Thus, the purpose of this pilot study was to determine the effects of a limited intervention using resistance bands on maternal muscle soreness when performed during the second and third 
trimesters of pregnancy. The main finding was that resistance band training during the second and third trimesters did not reduce upper or lower body muscle soreness, however, the mean values were in the expected direction. In addition, it was found that the exercise group had an increased likelihood of having a vaginal birth, while not negatively affecting the growth of the fetus. Lastly, limiting the amount of intervention resulted in a high adherence rate to the program, which is clinically important to keep women active throughout pregnancy.

\section{Maternal Outcomes}

There was no statistically significant difference found in maternal weight gain between the two groups, which supported the hypothesis. Thus, training with resistance bands did not negatively affect weight gain in the women in the exercise group.

It was hypothesized that there would be a reduction in upper body muscle soreness post-birth because the women in the exercise group performed resistance exercises using muscles that would be used during delivery. While not statistically significant, the results supported the hypothesis in that the mean values were in the expected direction. Exercises were specifically chosen (Table 1) based on muscle groups commonly used during labor and delivery. One potential reason that no significant difference was found could be that the intensity was not high enough. The women performed the resistance exercises at an RPE of 5-6 (somewhat hard), however, women push at a near-maximal level during labor and delivery, thus the intensity may have been too low to have a significant effect. Further, some women progressed through all of the given band intensities originally prescribed and thus they started using two bands at once (i.e., red and yellow) to increase the intensity. Thus, while the resistance was to be "somewhat hard," throughout the entire program, many may have benefitted from more intense band levels as they were not able to reach a "somewhat hard" intensity given the colors provided.

Another reason that there was no significant difference could be that women performed dynamic exercises rather than isometric exercises. We chose to implement dynamic exercises for two main reasons, 1) dynamic exercises serve a more functional purpose for activities of daily living and 2) isometric exercises, if not performed correctly, often lead to improper breathing patterns (i.e., Valsalva maneuver). During labor and delivery, the women underwent a series of sustained and repeated isometric contractions, thus, dynamic exercises may not have been as beneficial as isometric exercises. While this was taken into consideration when developing the program, we did not think it was safe to encourage women to perform isometric exercises for fear of improper breathing techniques, thus reducing oxygen to the fetus, especially during the independent sessions. Therefore, it is possible that increasing the intensity and/or switching the type of muscle action may affect upper body muscle soreness more after birth.

It was hypothesized there would be a reduction in lower body muscle soreness because the muscles used during resistance training would be used during delivery. The mean change score in lower body muscle soreness did not show a statistically significant difference, but the mean change scores were in the expected direction. Women in the exercise group experienced a mean change in lower body soreness of -0.50 and women in the standard care group experienced a mean change of -1.80 . Therefore, both groups experienced an increase in lower body muscle soreness following birth; however, on average, the exercise group experienced less lower body muscle soreness following birth than the standard care group. As stated above, a lack of statistical significance may be due to the intensity of the program and/or type of muscle action However, this is the first pilot study examining muscle soreness post-birth and thus it is important to confirm these results in a larger and more diverse sample.

\section{Birth Outcomes}

When comparing the exercise and standard care groups, there was no statistically significant difference in gestational age at birth, which supported the hypothesis. These results were corroborated by other studies that found similar results with similar training programs [8-10]. One such example was women who performed three training sessions per week for 35 minutes of resistance training and toning exercises. There was no statistically significant difference in gestational 
age between the training and control groups [9]. Because no significant differences were observed, this demonstrates that resistance-training programs, of this type and intensity, do not negatively affect the growth of the fetus or lead to premature deliveries, which is a clinically relevant finding.

There were also no statistically significant differences between the groups in length of maternal effort (i.e., amount of time pushing) and length of second stage of labor which did not support the hypotheses. It was expected that the women in the exercise group would have gained muscular strength and thus be able to push harder leading to a shorter delivery time. While contradictory to our hypotheses, these results are supported by a study conducted by Barakat et al. and colleagues in which women performed light to moderate toning and resistance training exercises 3 times per week and found no difference between exercise and control groups for mean dilation, expulsion, and childbirth time [11]. Both the current study and the study completed by Barakat et al. and colleagues had a light to moderate intensity resistance training program completed three times per week. Perhaps the intensity of the current program did not create a large enough stimulus to affect length of maternal effort. In addition, the majority of the women in the standard care group did not reach the second stage of labor because they went into a cesarean birth, making comparisons difficult.

Lastly, it was found that when comparing mode of birth, the exercise group had significantly more vaginal births than the standard care group $(p=.05)$, which supported the hypothesis. To emphasize this finding, there were zero women in the exercise group who went into an unscheduled cesarean birth, compared to 4 women in the standard care group. This provided support that performing muscle strengthening exercises allowed women in the exercise group to complete a vaginal birth without complications. Further, because the groups were similar upon randomization, including activity levels and parity, this finding is particularly important. These findings are corroborated by previous research. Barakat et al. randomized 290 women into a control or exercise group (3, 40-45 minute resistance training sessions/week) [12]. In the exercise group, 22 $(15.9 \%)$ of the women had cesarean births, as opposed to 35 (19.1\%) women in the control group. In a study by Tinloy et al., 3006 women self-reported activity levels during pregnancy and those who exercised the most minutes $(\geq 150)$ each week had the lowest number of cesarean births $(p=.002)$ [13]. In a study by Hall and Kaufmann, 845 participants performed exercise sessions with aerobic training and weight lifting and found a lower incidence of cesarean sections between groups [14]. Most recently, a meta-analysis performed on 16 studies found that structured aerobic or resistance exercise programs performed during pregnancy decreased the risk of a cesarean birth by 15\% [15]. Nevertheless, there are some studies that found no significant difference between groups and mode of birth $[5,11,16]$. While the findings on resistance training and mode of birth are contradictory, none of the studies found an increase in incidence of cesarean births in the exercise group. Therefore, the findings from the current study and previous research lead us to believe that resistance training during pregnancy can decrease the incidence of cesarean births, or at the very least not increase the incidence of cesarean births, which decreases recovery time for the mother after birth. This is a clinically relevant finding because a spontaneous vaginal birth is the preferred mode which leads to a shorter maternal recovery time, avoidance of surgical complications, and benefits to the fetus such as decreased respiratory issues.

\section{Newborn Outcomes}

When comparing newborn outcomes between the standard care and exercise groups, it was found that there were no statistically significant differences between newborn weight, length, and Apgar scores at one and 5 minutes. These findings supported the hypotheses. These data suggest that performing a resistance band-training program during the second and third trimesters of pregnancy is safe and leads to no adverse effects on fetal growth. Results from this study agree with findings from other studies showing no significant difference found between groups for newborn weight [ $\underline{3}, \underline{10}, \underline{17}]$ and newborn length [10]. Two studies concluded that there were no significant difference between Apgar scores at one and 5 minutes, which corroborates the current data $[3,9]$ demonstrating no adverse effects on how the newborn handles the birthing process. 


\section{Limitations}

The primary limitation of this pilot study was a small, homogeneous sample size. The demographic characteristics of the participants were similar to those in the area where the study was conducted, making the results less generalizable to different populations. While power was limited, mean values for muscle soreness were in the expected direction and no other research group has examined this variable to the authors' knowledge. Thus, replicating similar methodology with a larger sample size will be able to refute or corroborate the current findings. Another limitation was that the questions in the surveys were self-reported potentially leading to inaccuracies if there were errors when participants reported answers or if they perceived the questions (or pain or muscle soreness) differently. To counteract differences in perception of muscle soreness, a change score was calculated, thus the within-subject error was minimized. Lastly, as women progressed through the program, they felt they could perform the movements at a higher intensity than was possible with the Therabands ${ }^{\circledR}$ provided. We may have had statistically significant results if women had the opportunity to further increase the intensity of the resistance training program.

\section{Strengths}

This pilot study was a randomized controlled trial and was purposefully designed to limit the amount of intervention of the training program making it more practical. In other studies, a limitation was maintaining participant adherence [17, 18]. In the Haakstad and $B \varnothing$ study, sedentary women were asked to attend 2 out of the 360 minute fitness class offered each week for a minimum of 12 weeks [17]. Adherence was difficult as only $40 \%$ of participants attended $80 \%$ or more of the exercise sessions. Fieril et al. conducted a similar study to examine the effects from a supervised, self-rated moderate-tovigorous resistance exercise training during pregnancy. Of the 92 participants, $22 \%(n=20)$ did not complete the intervention [18]. These findings suggest that adherence is a barrier to exercise programs with a large time commitment. Thus, the current resistance training program used limited intervention, making it easy to administer and implement into the daily lives of the participants. The overall adherence rate was $>98 \%$ of all training sessions (approximately 45 total training sessions [3 sessions/week $x 15$ weeks]). Anecdotally, the women assigned to the exercise group were pleased with the program primarily because of the limited intervention. Consequently, utilizing a limited intervention increased the practicality for women and ensured it to be a versatile mode of exercise during pregnancy and accommodate individual lifestyles. Contacting the women each week kept the participants accountable for completing the sessions, ensuring they followed the protocol. Thus, the current study design was practical for both the investigators and participants. The one-on-one sessions provided a "personal training" aspect, creating accountability and allowing the women to build relationships as the pregnancy progressed. While the intensity of the program was a limitation, although not originally intended, using resistance bands made it cost efficient (approximately \$5/ participant) which increased practicality.

Lastly, and perhaps most importantly, the exercise program kept women active during their second and third trimesters, when physical activity generally declines, especially during the third trimester of pregnancy [4]. As pregnancy progresses, mothers gain weight, shifting their center of gravity [19] making them more uncomfortable [18], thus offering options, such as resistance bands, that would increase or maintain activity levels from prepregnancy and/or first and second trimesters is of the utmost importance as it is well documented the benefits of exercise during pregnancy far outweigh the risks [1].

\section{Conclusion}

In conclusion, in this pilot study, it was found that a limited intervention resistance band training program performed 3 days/week over the second and third trimesters of pregnancy showed no change in maternal upper and lower muscle soreness; however, the mean values were in the expected direction. Of note, women who completed the resistance band training did have a higher percentage of vaginal births than women in the standard care group. Further, there were no adverse effects on other maternal, birth, and newborn outcomes demonstrating that this was a safe program to implement. Thus, while the sample size was small, these findings have clinical importance, even if they are not statistically significant due to 
limited power. Due to the practicality (i.e., limited intervention) and cost-effectiveness of resistance bands, this program can be a versatile mode of exercise during pregnancy and accommodate individual lifestyles which is important for implementation in a clinical setting. Lastly, additional research on a variety of resistance training methodologies during pregnancy (intensities, equipment, and progression) is needed to continue moving the field forward in establishing guidelines that are safe and effective for both the mother and fetus.

\section{Acknowledgments}

Winona State University Foundation, Winona Health staff and nurses, Jack Keilty and Katie Swanson. This work was supported by a Special Project Foundation Grant from the Winona State University Foundation.

\section{References}

1. American Congress of Obstetricians and Gynecologists. Exercise During Pregnancy. http://www.acog.org/Patients/ FAQs/Exercise-During-Pregnancy. Updated August 2011. Accessed March 21, 2016.

2. Mark W, William H, Phillip A, et al. (2007) Resistance exercise in individuals with and without cardiovascular disease: 2007 update: A scientific statement from the American Heart Association Council on Clinical Cardiology and Council on Nutrition, Physical Activity, and Metabolism. Circulation. 116:572-584.

3. Ruben B, Alejandro L, Jonatan R (2009) Resistance exercise training during pregnancy and newborn's birth size: A randomised controlled trial. Int J Obes. 33:1048-1057.

4. Kelly E, David S, Sara H (2004) Leisure-time physical activity among pregnant women in the U.S. Paediatr Perinat Epidemiol. 18:400-407.

5. Lene H, Kari B (2015) Effect of a regular exercise programme on pelvic girdle and low back pain in previously inactive pregnant women: A randomized controlled trial. J Rehabil Med. 47:1-6.

6. Lisa CT, Michael S, Dawn R, et al. (2004) Development and validation of a Pregnancy Physical Activity Questionnaire. Med Sci Sports Exerc. 36:1750-1760.

7. Alan D, Ronald M, Paul W (1990) Effects of ibuprofen on exercise-induced muscle soreness and indices of muscle damage. Br J Sports Med. 24:191-195.

8. Erin W, James P, Karin P (2014) Resistance training during pregnancy and perinatal outcomes. J Phys Act Health. 11:1141-1148.

9. Ruben B, James S, Alejandro L (2008) Does exercise training during pregnancy affect gestational age? A randomised controlled trial. Br J Sports Med. 42:674-678.

10. Ardiana M, Myrvete $P$, Zana $P$, et al. (2014) The impact of exercise during pregnancy on neonatal outcomes: A randomized controlled trial. J Sports Med Phys Fitness. 54:802-808.

11. Ruben B, Jonatan R, James S, et al. (2009) Type of delivery is not affected by light resistance and toning exercise training during pregnancy: A randomized controlled trial. Am J Obstet Gynecol. 201:590e1-590e6.

12. Ruben B, Mireia P, Lopez C, et al. (2012) Exercise during pregnancy reduces the rate of cesarean and instrumental deliveries: Results of a randomized controlled trial. J Matern Fetal Neonatal Med. 25:2372-2376.

13. Jennifer T, Cynthia C, Junjia Z, et al. (2014) Exercise during pregnancy and risk of late preterm birth, cesarean delivery, and hospitalizations. Women's Health Iss. 24:99-104.

14. Douglas H, David K (1987) Effects of aerobic and strength conditioning on pregnancy outcomes. Am J Obstet Gynecol. 157:1199-1203.

15. Iris D, Bengt K, Michel B (2014) Effect of physical activity during pregnancy on mode of delivery. Am J Obstet Gynecol. 211: 401.e1-401.e11.

16. Vlatka T, Goran S, Jozo T, et al. (2013) The effect of maternal exercise during pregnancy on abnormal fetal growth. Croatian Med J. 54:362-368.

17. Lene H, Kari B (2011) Exercise in pregnant women and birth weight: A randomized controlled trial. BMC Pregnancy Childbirth. 11:66.

18. Karolina F, Monika O, Anna G, et al. (2014) The efficacy of moderate-to-vigorous resistance exercise during pregnancy: A randomized controlled trial. AOGS. 4:35-42.

19. Agnieszka OB, Bogdan B, Andrzej M, et al. (2014) Comparison of static postural stability in exercising and non-exercising women during the perinatal period. Med Sci Monit. 20:1865-1870.

20. Vivian H (2010) Advanced Fitness Assessment and Exercise Prescription. 6th Edition, Human Kinetics, Champaign, USA. 